\title{
REFRACTIVE ERRORS AND ITS ASSOCIATED FACTORS AMONG UNDERGRADUATE MEDICAL STUDENTS IN KATHMANDU
}

\author{
Rizyal A, Sunrait JS, Mishal A
}

Department of Ophthalmology, Nepal Medical College Teaching Hospital, Attarkhel, Gokarneshwor-8. Kathmandu, Nepal.

\begin{abstract}
Refractive error is a defect in the optical system of the eye which prevents light from being brought to a single point focus on the retina, thus reducing normal vision. This optical defect is the second most common cause of visual impairment globally as well in Nepal. At present, there are 285 million visually impaired people in the world. An estimated 4 out of 5 visual impairment (80\%) can be prevented or cured, uncorrected refractive errors are the leading cause (42\%) followed by cataract (33\%). A descriptive cross sectional study was conducted to determine the proportion of undergraduate medical students with refractive errors in Nepal Medical College, and to identify factors associated with it. A total of 210 medical students volunteered for this study, with 100 males (47.6\%) and 110 females (52.4\%). The age of these students were between 18 to 26 years, with an average of 20.5 years. The proportion of medical students with refractive error was slightly more than half (51.4\%), with simple myopia being the leading type (42.9\%), followed by astigmatism (7.1\%) and simple hypermetropia (1.4\%). Parental history of refractive error was observed to be significantly associated with that of the medical students. There was also a significant association between refractive error and the daily use of mobile phones and laptops. However, years spent in medical education were not observed to be significant.
\end{abstract}

\section{KEYWORDS}

Associated factors, astigmatism, medical students, myopia, refractive error

\section{CORRESPONDING AUTHOR}

Dr. Aparna Rizyal,

Associate Professor, Department of Ophthalmology,

Nepal Medical College Teaching Hospital,

Attarkhel, Gokarneshwor-8, Kathmandu, Nepal

Email: aparnarizyal@yahoo.com 


\section{INTRODUCTION}

Refractive error is a defect in the optical system of the eye which prevents light from being brought to a single point focus on the retina, thus reducing normal vision. ${ }^{1}$ Refractive errors are the second most common cause of visual impairment globally as well in Nepal. ${ }^{2,3}$

At present, there are 285 million visually impaired people in the world. Four out of 5 such impairment can be prevented or cured. Uncorrected refractive errors are the leading cause accounting for $42 \%$, followed by cataract accounting for $33 \% .{ }^{2}$ Refractive errors are becoming more of a problem in many societies, with prevalence rates of myopia in many Asian countries reaching epidemic proportions. ${ }^{3}$ Though correctable, using spectacles and contact lenses, refractive errors present a reasonably large economic burden. Poor vision in students has an adverse influence on their future life, as it affects productive performance in education, thus in long term affecting the economic burden of the country.

In the past few decades, numerous epidemiological studies have provided information on the prevalence and risk factors for refractive errors. Majority of studies on refractive errors have however, focused more on school going children and the general population. Studies on refractive errors among the medical students have been conducted, but to a lesser degree than the school children. The prevalence rate of myopia in Singapore medical students was $82 \%$, while that of astigmatism was more than $70 \%{ }^{4}$ Another study in Taiwan showed that more than $90 \%$ of Taiwanese medical students were myopic. ${ }^{5}$ In contrast, similar studies on medical students in Denmark and Norway yielded relativelylow prevalence rates of myopia accounting for $50 \%$ and 50.3\%, respectively. ${ }^{6,7}$ Medical students in India are reported to have a high prevalence of refractive errors ranging from $54 \%$ to $74 \% .{ }^{8-16}$

In Nepal, a small majority of these studies have been conducted on school children and the general population. A population based study carried out among school children in Mechi, East Nepal showed that $2.9 \%$ had some amount of visual morbidity with refractive error accounting for $56 \%$ of that morbidity. ${ }^{18} \mathrm{~A}$ study on ocular morbidity among school children in Kathmandu, showed refractive error as the commonest ocular morbidity accounting for $8.1 \%{ }^{19}$ Similar study on ocular morbidity among private school children showed refractive error as the most common morbidity with $21.9 \% .{ }^{20} \mathrm{~A}$ study on refractive error in urban and rural children showed refractive errors as $19.8 \% .{ }^{21} \mathrm{~A}$ hospital based cross sectional study on refractive error showed simple myopia as the most prevalent type of refractive error accounting for $27 \%$ of all cases. ${ }^{22}$

In Nepal, there has been no comparable study available in the specialized group of medical students, who are subjected to a lot of visual stress of higher education. In addition, no study that attempts to identify the factors associated with refractive errors has been conducted till date. Hence, this study was conducted to determine the proportion of undergraduate medical students with refractive errors in Nepal Medical College, and to indentify factors associated with it.

\section{MATERIALS AND METHODS}

This was a descriptive cross sectional study conducted at the Ophthalmology department of Nepal Medical College Teaching Hospital, from September to December 2018. A complete enumeration of the undergraduate medical students of 1st year, 3rd year and final year was performed. Ethical approval was taken from the Institutional Review Committee of Nepal Medical College (NMC-IRC). Informed and verbal consent of each participant was obtained before the study after informing the participants of the purpose of the study and confidentiality of results.

All students who volunteered for this study were requested to provide demographic data. Medical students suffering from any ocular diseases (glaucoma, ocular injury, or who had undergone refractive surgery LASIK) were excluded from the study. A detailed history, including previous history of refractive error, spectacle/contact lens use, and parental history of refractive error were taken. History about the working activities of the students, daily use of electronic gadgets (laptops/desktops) and mobile phones was taken. Visual acuity was recorded monocularly, on an internally illuminated standard Snellen's chart at 6 meters. Retinoscopy was performed in a dark room at a working distance of $50 \mathrm{~cm}$, with the patient fixing on a target at 6 metre. Streak retinoscopy was performed. Those students having visual acuity of less than 6/6 on Snellen's chart were subjected to subjective refraction. Cycloplegics were not used. Diagnosis of refractive error was made when the magnitude of refractive error was equal to or more than 0.50DSph. Those errors which required only cylindrical correction were considered as simple astigmatism.

Data were entered in Excel worksheet and analyzed using SPSS version 16. Association between refractive errors and explanatory variables were determined using Chi square test. A p value of $<0.05$ was considered significant.

\section{RESULTS}

A total of 210 undergraduate medical students participated in this study, with 100 males and 110 females comprising $47.6 \%$ and $52.4 \%$ respectively. The age of these students varied from 18 to 26 years, the average being 20.5 years (Table-1). Of the total, 80 students (38.9\%) were in the first year, 67 (31.9\%) were in the third year and $63(30.0 \%)$ were in the final year of MBBS studies (Table-2). 
Table-1: Demographic profile of the MBBS students

\begin{tabular}{|ccccc|} 
Age (years) & \multicolumn{2}{c}{ Males } & \multicolumn{2}{c}{ Females } \\
& $\mathrm{n}$ & $\%$ & $\mathrm{n}$ & $\%$ \\
$18-20$ & 34 & 16.2 & 34 & 16.2 \\
$21-23$ & 62 & 29.5 & 75 & 35.7 \\
$24-26$ & 4 & 1.9 & 1 & 0.5 \\
Total & 100 & 47.6 & 110 & 52.4 \\
\hline
\end{tabular}

Table-2: Academic year of the MBBS students

\begin{tabular}{|c|c|c|c|c|}
\hline \multirow[t]{2}{*}{$\begin{array}{l}\text { No of } \\
\text { students }\end{array}$} & \multicolumn{2}{|c|}{ Males } & \multicolumn{2}{|c|}{ Females } \\
\hline & $\mathbf{n}$ & $\%$ & $\mathbf{n}$ & $\%$ \\
\hline $1^{\text {st }}$ year & 41 & 19.5 & 39 & 18.6 \\
\hline $3^{\text {rd }}$ year & 30 & 14.3 & 37 & 17.6 \\
\hline Final year & 29 & 13.8 & 34 & 16.2 \\
\hline Total & 100 & 47.6 & 110 & 52.4 \\
\hline
\end{tabular}

Table-2 shows the total number of students who volunteered for this study and the breakup of students from each academic year. Approximately one out of 5 of the total students were male students from the first year (19.5\%), followed by a similar percentage (18.6\%) of females from the first year.

\begin{tabular}{|llll|}
\multicolumn{4}{|c|}{ Table-3: Frequency of errors of refraction of } \\
the MBBS students \\
Type of refractive error & $\mathbf{n}$ & $\%$ & P value \\
Simple Myopia & 90 & 42.9 & \\
Simple Hypermetropia & 3 & 1.4 & 0.02 \\
Astigmatism & 15 & 7.1 & \\
Total & 108 & 51.4 & \\
\hline
\end{tabular}

Table- 3 reveals the frequency of errors of refraction. Slightly more than half of the students (51.4\%) had some form of refractive error, with the most common being simple myopia which accounted for $42.9 \%$, followed by simple astigmatism of $7.1 \%$. Simple hypermetropia accounted for only $1.4 \%$ of all cases. Thus, the types of refractive error were not uniformly distributed. This finding was consolidated by Chi square test. $(p$ value $=0.02)$

Table-4: Types of refractive error according to the academic year

\begin{tabular}{|lccccccc} 
Students & $\begin{array}{c}\text { Simple } \\
\text { myopia }\end{array}$ & \multicolumn{2}{c}{$\begin{array}{c}\text { Simple } \\
\text { hyper- } \\
\end{array}$} & $\begin{array}{c}\text { metropia } \\
\text { n }\end{array}$ & $\begin{array}{c}\text { Astig- } \\
\text { matism }\end{array}$ & $\begin{array}{c}\text { P } \\
\text { value }\end{array}$ \\
$1^{\text {st }}$ year & 26 & 12.4 & 3 & 1.4 & 7 & 3.3 & \\
$3^{\text {rd }}$ year & 37 & 17.6 & 0 & 0 & 4 & 1.9 & \\
Final year & 27 & 12.9 & 0 & 0 & 4 & 1.9 & 0.06 \\
Total & 90 & 42.9 & 3 & 1.4 & 15 & 7.1 & \\
\hline
\end{tabular}

The most common refractive error was simple myopia accounting for $42.9 \%$ of all cases, followed by simple astigmatism $7.1 \%$ and hypermetropia $1.4 \%$. Slightly more than half of the students had some sort of refractive errors (51.4\%). The students of the third year had the maximum number of myopes (17.6\%), followed by final year and first year students who had similar percentage of $12.9 \%$ and $12.4 \%$ respectively (Table-4). The association between simple myopia and years spent in present medical education was not statistically significant.

\begin{tabular}{|c|c|c|c|}
\hline \multirow[t]{2}{*}{$\begin{array}{l}\text { Students with } \\
\text { refractive error }\end{array}$} & \multicolumn{2}{|c|}{$\begin{array}{l}\text { Parents with } \\
\text { refractive error }\end{array}$} & \multirow[t]{2}{*}{$\begin{array}{c}\mathbf{P} \\
\text { value }\end{array}$} \\
\hline & Presence & Absence & \\
\hline Presence & 98 & 10 & \multirow{2}{*}{0.001} \\
\hline Absence & 26 & 76 & \\
\hline
\end{tabular}

Of the total 108 students with refractive error, 98 students were those whose parents also had the same problem. Among 76 parents who had no refractive error, only 26 students had refractive error. (Table-5)The association between refractive error and parental history was observed significant.

\begin{tabular}{lccc|}
\multicolumn{4}{|c|}{ Table-6: Refractive errors and use of mobile } \\
phones & & \\
$\begin{array}{l}\text { Average use of } \\
\text { mobile phones } \\
\text { daily (hours/day) }\end{array}$ & $\begin{array}{c}\text { Students with } \\
\text { refractive errors }\end{array}$ & $\begin{array}{c}\text { P } \\
\text { value }\end{array}$ \\
& $\begin{array}{c}\text { Present } \\
\text { n }\end{array}$ & $\begin{array}{c}\text { Absent } \\
\text { n }\end{array}$ & \\
& 32 & 26 & \\
$\leq 2$ hours & 32 & 62 & 0.02 \\
2- 3 hours & 68 & 14 & \\
$\geq 4$ hours & 8 &
\end{tabular}

It was observed that almost an equal number of students with or without refractive errors used mobile phones for 2-3 hours daily (Table-6). Refractive error was significantly associated with the daily use of mobile phone (hours/day).

\begin{tabular}{|lccc|}
\hline \multicolumn{4}{|c|}{ Table-7: Refractive errors and use of laptop/ } \\
desktop & & \\
\hline $\begin{array}{l}\text { Average use of } \\
\text { laptop/desktop } \\
\text { daily (hours/day) }\end{array}$ & $\begin{array}{c}\text { Students with } \\
\text { refractive errors }\end{array}$ & $\begin{array}{c}\text { P } \\
\text { value } \\
\text { Present } \\
\text { n }\end{array}$ & $\begin{array}{c}\text { Absent } \\
\mathbf{n}\end{array}$ \\
& 77 & 59 & \\
$\leq 2$ hours & 18 & 17 & 0.004 \\
2- 3 hours & 13 & 26 & \\
$\geq 4$ hours & & & \\
\hline
\end{tabular}

Majority of the students (64.7\%) spent less than 2 hours daily on their laptops/desktops. Refractive error was observed to be significantly associated with the use of laptops/desktop. (Table-7) 


\section{DISCUSSION}

Studies on refractive errors among medical students have been conducted in different parts of the globe. This study estimated that slightly more than half (51.4\%) of the undergraduate medical students of Nepal Medical College had refractive errors. This result is in accordance with studies in the Scandinavian countries, where the prevalence rate of refractive errors among the medical students was $50.3 \%{ }^{6-7}$ and in India, where it varied from 54-73\%. .-16 $^{8-}$ However there was a much higher prevalence of $80-90 \%$ among medical students in Singapore ${ }^{4}$ and Taiwan. ${ }^{5}$

Among the students who had refractive errors (51.4\%), the leading type was simple myopia seen in $42.9 \%$, followed by simple astigmatism in $7.1 \%$ and simple hypermetropia in $1.4 \%$. These findings are consistent with various studies done in different parts of India. A cross-sectional study done to assess myopia in medical students in South India showed that the prevalence rate of myopia was $58 \% .{ }^{8} \mathrm{~A}$ risk factor based study on myopia conducted by Wakode estimated prevalence of myopia as $54.9 \%$ of the study population. ${ }^{10} \mathrm{~A}$ study on refractive errors among medical students in Baroda, India estimated the prevalence of refractive error as $54.6 \%$, with myopia accounting for $51.9 \% .^{12} \mathrm{~A}$ similar study in Odisha, India estimated a similar prevalence of refractive error as $56 \%$, with myopia accounting for $54.5 \%$ followed by astigmatism $31.3 \% .{ }^{14} \mathrm{~A}$ study of refractive errors among medical students in Lucknow, done by Garg $e t a l^{16}$ reported the prevalence of refractive error as 54\%, with a higher prevalence of myopia accounting for $77.7 \%$. Studies on medical students in Denmark and Norway yielded a relatively- low prevalence rates of myopia accounting for $50 \%$ and $50.3 \%$, respectively. ${ }^{6,7}$ A similar study of refractive errors among medical students in Saudi Arabia, also reported a similar prevalence of refractive error as $58.6 \%$, with myopia accounting for $53.7 \% .{ }^{23}$ Most of these studies have reported that myopia is the most prevalent refractive error among the students. This could be due to the intensive studying and exposure to performing near work that a medical curriculum requires.

A Singapore based study among medical students reported the prevalence rate of myopia was 8 out of $10(82 \%)$, while 7 out of 10 had astigmatism (70\%). ${ }^{4}$ Another study of 345 medical students in Taiwan showed that 9 out of $10(90 \%)$ of Taiwanese medical students were myopic. ${ }^{5}$ The higher prevalence of myopia among the Chinese people could be due to their ethnicity.

This study estimated that slightly more than half of the students $(51.4 \%)$ had some form of refractive error, with the most common being simple myopia which accounted for $42.9 \%$, followed by simple astigmatism of $7.1 \%$. This is in accord with similar studies in India where the prevalence of myopia ranged from 51.9 to $77.7 \% .^{8-16}$ The distribution of the types of refractive error were found to be statistically significant $(\mathrm{p}<0.05)$. This study revealed that simple hypermetropia accounted for only $1.4 \%$ of all cases. This is consistent with a study in Saudi Arabia where a similar prevalence of hypermetropia was reported. ${ }^{24}$ This differed from other studies where hypermetropia had a higher prevalence. ${ }^{15,16}$

Of the total 108 students with refractive error, 98 students were those whose parents also had the same problem. Among 76 parents who had no refractive error, only 26 students had refractive error. The association between refractive error and parental history was also observed to be significant. Similar association was found in a study of refractive errors among medical students performed in Manipal, India as reported by Jessica and Kamath ${ }^{25}$ and in a study of prevalence of refractive errors and its associated factors among female university students as reported by Shaikh in Saudi Arabia. ${ }^{24}$

It was observed that almost an equal number of students with refractive errors and without used mobile phones for 2-3 hours daily. Refractive error was significantly associated with the daily use of mobile phones and use of laptops/desktop. This is consistent with the study among female university students conducted in Saudi Arabia. ${ }^{24}$

In conclusion, myopia was the most prevalent refractive error among the medical students. The distribution of the types of refractive error was statistically significant. However, the association between simple myopia and years spent in medical education was not statistically significant.

There was a significant association however between the refractive error status of the students and parental history of refractive error. Refractive error was also significantly associated with the daily use of mobile phones and use of laptops/desktop.

\section{ACKNOWLEDGEMENT}

The authors would like to thank all those students who volunteered for this study.

\section{REFERENCES}

1. William F Ganong.Review of Medical Physiology. $22^{\text {nd }}$ Edition.2005; 156.

2. Mariotti S.P, Pascollini D.Global estimates of visual impairment:2010. Br J Ophthalmol 2012; 96: 614-8.

3. World Health Organization (1997) "Elimination of avoidable visual disability due to refractive error" Report of an informal planning meeting WHO/ PBL/00.79, 1997; pp: 6-10.

4. Chow YC, Dhillon B, Chew PTK, Chew SJ. Refractive errors in Singapore medical students. Singapore Med J 1990; 31: 472-3.

5. Lin LKL, Shif YF, Lee YC, Hung PT, Hou PK. Changes in ocular refraction and its components among medical students. A 5-year longitudinal study. 
Optom Vis Sci 1996; 73: 495-8.

6. Fledelius HC. Myopia profile in Copenhagen medical students 1996-98. Refractive stability over a century is suggested. Acta Ophthalmol Scand 2000; 78: 501-5.

7. Midelfart A, Aamo B, Sjøhaug KA, Dysthe BE. Myopia among medical students in Norway. Acta Ophthalmol (Copenh) 1992; 70: 317-22.

8. Chalasani S, Jampala VK, Nayak P. Myopia among medical students - A cross sectional study in a South Indian Medical College. Al Ameen J Med Sci 2012; 5: 233-42.

9. Kathrotia RG, Dave AG, Dabhoiwala ST, Patel ND, Rao PV, Oommen ER. Prevalence and progression of refractive errors among medical students. Indian J Physiol Pharmacol 2012; 56: 284-7.

10. Wakode NS, Wakode SL, Ksheersagar DD. Risk factors for myopia in medical students. Int J Recent Trends Sci Technol 2013; 8: 09-11.

11. Sood RS, Sood A. Prevalence of myopia among the medical students in western India vis-à-vis the East Asian epidemic. J Dent Med Sci 2014; 13: 65-7.

12. Chaudhry R, Ali H, Sheikh NH. Frequency and underlying factors of myopia among medical students. Biomedica 2011; 27: 154-60.

13. Rajdeep P, Patel R. A study of refractive errors on students of Baroda Medical College. Indian J Res Reports Med Sci 2013; 3: 18-9.

14. Dey AK, Chaudhuri SK, Jana S, Ganguly P, Ghorai S, Sarkar A. Prevalence of refractive errors in medical students. Int J Health Sci Research 2014; 4:98-102.

15. Kshatri JS, Panda M, Tripathi RM. Prevalence, progression and association of corrected refractive errors:a cross-sectional study among students of a medical college of Odisha,India. Int J Community Med Public Health 2016; 3: 2916-20.

16. Garg P, Singh, Raza Yadav. Study of refractive errors in medical students. India J Clin Exp Ophthalmol 2018; 4: 518-20.
17. Gopalakrishnan Prakash MVS, Jha RK.A study of refractive errors among medical students in AIMST university, Malaysia .Indian Med J 2011; 105: 365-7.

18. Pokhrel GP,Negrel AD,Munroz SR,Ellwein LB. Refractive error in children:results from Mechi Zone, Nepal. Amer J Ophthalmol 2000; 129: 436-44.

19. Nepal BP,Koirala S,Adhikari Sharma AK.Ocular morbidity in school children in Kathmandu. Brit J Ophthalmol 2003; 87: 531-4.

20. Shrestha RK, Joshi MR, Ghising R, Pradhan P, Shakya S, Rizyal A. Ocular morbidity among school children in private schools of Kathmandu Valley: A prospective cross sectional study. Nepal Med Coll J 2006; 8: 43-6

21. Pokhrel A,Pokhrel PK,Das H, Adhikari S.The pattern of refractive error among school children in rural and urban settings of Nepal. Nepal J Ophthalmol 2010; 2: 114-20.

22. Rizyal A, Ghising R, Shrestha RK, Kansakar IK.Pattern of refractive error in a tertiary care hospital in Kathmandu. Nepal Med Coll J 2011; 13: 172-74.

23. Al-Rashidi SH,Albahouth A A,Althwini WA et al. Prevalence Refractive Errors among medical students of Qassim University, Saudi Arabia: Crosssectional descriptive study. Maced J Med Sci 2018; 6: $940-43$.

24. Shaikh SA, Alkhayyal MA, AlHammad AK et al. Prevalence of refractive errors and its associated factors among female students of King Saud University, Riyadh. World J Med Surg Ophthal 2016; 2; 1-11.

25. Jessica SD, Kamath SR. Study of refractive errors among medical students of Melaka Manipal Medical College at Manipal in India. Proceedings of the $4^{\text {th }}$ World Conference on Applied Sciences, Engineering and Technology. Kumamato University, Japan 2015 (24-26 October), ISBN 13:9781-9302221-4: 43-5. 